\title{
Conselho tutelar: constituição, características e funções
}

\author{
Denise Vichiato Polizelli ${ }^{1}$ \\ Vilma Aparecida do Amaral $^{2}$
}

\begin{abstract}
Resumo
o Conselho Tutelar é órgão não-jurisdicional, autônomo e permanente. Tem como principal objetivo zelar pelos direitos das crianças e dos adolescentes. Para desempenhar suas funções, ele deve fazer uso das estruturas determinadas pelo Estatuto da Criança e do Adolescente, sempre tendo em vista que se trata de um serviço público relevante para a sociedade.
\end{abstract}

Palavras-Chave: Conselho Tutelar; Constituição; Características; Funções; Escolha; Impedimentos.

\section{Introdução}

O título V do Estatuto da Criança e do Adolescente cria e define o Conselho Tutelar. Deve-se dizer que as disposições legais não são claras suficientes a ponto de não existirem dúvidas e divergências doutrinárias.

Antes de prosseguir com o estudo e análise da lei, é relevante registrar que poucos autores se preocupam com essa temática, de modo que a busca por esclarecimentos não foi uma tarefa fácil. Além disso, é perceptível que as soluções apresentadas, muitas vezes, são inaplicáveis à realidade. Desse modo, o presente trabalho foi elaborado na tentativa de desvendar o intuito do legislador quando da elaboração da lei e da criação do Conselho Tutelar, de acordo com o artigo inaugural.

\section{Desenvolvimento}

Art. 131. O Conselho Tutelar é órgão permanente e autônomo, não jurisdicional, encarregado pela sociedade de zelar pelo cumprimento dos direitos da criança e do adolescente, definidos nesta Lei.

Esse artigo institui a criação do órgão, indicando as características a ele inerentes: permanente, autônomo e não jurisdicional.

\footnotetext{
${ }^{1}$ Discente do curso de Direito da Universidade Estadual de Londrina, estagiária do Projeto de Extensão "ECA na Docência do Ensino Fundamental e M édio", sob orientação da Profa. Vilma A. do Amaral.

2 Docente do curso de Direito da universidade Estadual de Londrina.
} 
Permanente tem o sentido de ser duradouro e ininterrupto, como anotou Judá Jessé de Bragança Soares em Estatuto da Criança e do Adolescente Comentado (CURY, 2006, p. 446). Deve-se compreender também que esse órgão, independente dos membros que 0 compõe, deve ter seus trabalhos desenvolvidos em um fluxo constante, em acordo com 0 princípio da proteção integral, e não influenciável.

Autônomo significa independente, com liberdade para tomar decisões. Assim, ele não está submetido hierarquicamente a nenhum outro poder ou órgão.

Não jurisdicional significa que o órgão não pertence ao Poder Judiciário. Assim, suas funções são de caráter administrativo, ou seja, é um colegiado que representa a sociedade civil, defendendo interesses públicos, "[...] não the cabendo apreciar e julgar os conflitos de interesses (não-jurisdicional), função, esta, própria do Poder Judiciário." ${ }^{3}$

Além dessas três características apresentadas, o próximo artigo apresenta outras, que dessa vez estão relacionadas à sua composição, também de modo a limitar a permanência no cargo.

Art. 132. Em cada M unicípio haverá, no mínimo, um Conselho Tutelar composto de cinco membros, escolhidos pela comunidade local para mandato de três anos, permitida uma recondução.

Quando da publicação da lei, ela trazia uma disposição diversa acerca da escolha dos membros, que se dava por uma eleição em que os eleitores seriam os cidadãos locais, muito símile com a candidatura para um cargo político.

Lei posterior (Lei №. 8.242, de 12/10/19914) modificou o processo, assim os conselheiros são escolhidos pela comunidade local, em procedimento livremente estabelecido em lei municipal.

Uma vez ocupado o cargo, o conselheiro só poderá dar continuidade a essa função por mais um mandato consecutivo, ou seja, é permitida uma recondução. Assim, se os

${ }^{3}$ LIBERATI, Wilson D. et CYRINO, Caio B. Conselhos e fundos no estatuto da criança e do adolescente. São Paulo, Malheiros, 2003, 2aed., p.125 e 127, apud BRANCO, 2006. Disponível em: বttp://jus2.uol.com.br/doutrina/texto.asp?id=9192>. Acesso em: 15 mar. 2008.

${ }^{4}$ BRASIL. Lei $n$ - . 8.242, de 12 de outubro de 1991. Cria o Consel ho Nacional dos Direitos da Criança e do Adolescente (Conanda) e dá outras providências. Disponível em: বtttp:// www81.dataprev.gov.br/sislex/paginas/42/1991/8242.htm>. Acesso em: 11 maio 2008. 
mandatos não forem seguidos um do outro, nada impede um cidadão de desempenhar a função por diversas vezes, dependendo apenas de ser escolhido.

Esse artigo ainda estabelece que haverá, no mínimo, um Conselho Tutelar em cada município, ou seja, os municípios devem contar com uma disponibilidade de Conselhos de acordo com a demanda social, segundo a interpretação de M ilano e M ilano Filho (2004, arts. 131 a 135):

Conveniente, pois, a instalação dos Conselhos tutelares de acordo com a necessidade de cada Município e suas regiões; recomenda-se a instalação de mais de um conselho, observada sua estrita necessidade [...].

Cabe observar que, diante do descumprimento da determinação de instalar o Conselho Tutelar por parte do município, poderá ser acionado mediante mandado de injunção ou ação civil pública. (MUNIR, 2006, p. 447).

Conforme prevê 0 art. 5으, inciso LXXI, da Constituição Federal, cabe mandado de injunção sempre que a falta de norma regulamentadora torne inviável o exercício de direitos e liberdades constitucionais e das prerrogativas inerentes à nacionalidade, à soberania e à cidadania (MORAES, 2002, p. 179). Assim, o objetivo principal é suprir uma omissão do Poder Público, qual seja, a ausência de norma regulamentadora de dispositivo constitucional. Poderá propor a ação qualquer pessoa que tenha 0 exercício de direito, liberdade ou prerrogativa impedido, sendo possível também o mandado de injunção coletivo, que pode ser proposto no interesse de categorias, por qualquer entidade associativa nos termos do art. 50, XXI (DA SILVA, 2006, p. 462).

Já a ação civil pública "é aquela pela qual o órgão do Ministério Público ou outros legitimados ativos (as pessoas jurídicas, públicas ou privadas) ingressam em juízo com o intuito de proteger o patrimônio público e social, o meio ambiente, o consumidor, ou, ainda, quaisquer interesses difusos e coletivos, pleiteando a fixação da responsabilidade e, conseqüentemente, a reparação pelos danos causados. ${ }^{5}$

Dando continuidade à interpretação legislativa, é relevante destacar a disposição "composto de cinco membros", matéria muito discutida na doutrina. Na prática, quando da ausência de conselheiro(s) permanente, não importando a causa, o órgão se mantém

\footnotetext{
${ }^{5}$ MAZZWL, Hugo Nigro. Portal do Ministério Público do Estado do Rio Grande do Sul. Disponível em: «ttp://www.mp.rs.gov.br/imprensa/desc_palavra.ptr/17.htm>. Acesso em: 11 maio 2008.
} 
funcionando mesmo com número inferior ao legalmente estabelecido, sem previsão legal de como proceder. Entretanto, deve-se assegurar a característica de órgão colegiado do Conselho Tutelar. Assim, pertinente a observação:

A única alternativa restante, embora drástica e nem um pouco simpática, é o reconhecimento de que o Conselho Tutelar, uma vez que passe a contar com um número de integrantes inferior àquele fixado, de forma invariável, pelo art.132 da Lei $\mathrm{n}$ - 8.069/90, e não mais existam suplentes a convocar para assumirem a(s) vaga(s) existente(s), de fato e de direito estará automaticamente DISSOLVIDO ${ }^{6}$

Após ser dissolvido, novas eleições devem ser convocadas para a escolha dos novos membros. Durante a ausência do Conselho Tutelar, suas funções devem ser desenvolvidas pelo Juiz da Infância e da Juventude.

Para que os membros do Conselho sejam escolhidos, a Lei determinou alguns requisitos, que devem ser observados quando da propositura da candidatura ao cargo, conforme traz o artigo 133.

Art. 133. Para a candidatura a membro do Conselho Tutelar, serão exigidos os seguintes requisitos:

I - reconhecida idoneidade moral;

II - idade superior a vinte e um anos;

III - residir no município.

Os requisitos estabelecidos pelo Estatuto são mínimos, sendo que a lei municipal poderá ampliá-los. Milano e Milano Filho(2004, arts. 131 a 135) assim dispõem acerca da ampliação:

Conveniente a especialização de candidatos, ainda, nas áreas da saúde, educação, assistência social ou psicológica, com reconhecida experiência com crianças e adolescentes, mesmo porque, esse trabalho prévio de seleção de candidatos evitará problemas futuros, não podendo ser o cargo ocupado por um político, e sim por um profissional da área de atendimento.

Deve-se atentar para o fato de que nem sempre a demanda de candidatos ao cargo é tão completa, não dispondo dessas características enumeradas por Milano e Milano Filho.

${ }^{6}$ DIGIÁCOMO, Murillo José. Algumas considerações sobre a Composição do Conselho Tutelar. Portal do Ministério Público do Estado do Paraná. Disponível em: «ttp://www.mp.pr.gov.br/cpca/telas/ca_doutrina_cd_ct_13.html>. Acesso em: 15 mar. 2008. 
Assim, para Digiácomo ${ }^{7}$ os conselhos devem ser dotados de uma ESTRUTURA DE "RETAGUARDA", ou seja, não necessariamente os conselheiros seriam altamente especializados, mas teriam acesso a uma equipe técnica para auxiliá-los nas questões mais complexas.

Para que a lei municipal disponha outros requisitos, antes deve cumprir com os que foram estabelecidos pela lei federal. Assim, a idoneidade moral pode ser entendida como a condição de quem é adequado, apto para executar as funções do órgão, no prazo e nas condições devidas ${ }^{8}$, também levando em conta o histórico social e experiência de vida.

Contudo, a idoneidade moral é uma presunção jurídica e deve ser prévia ao ato de formalização da candidatura. No caso de se verificar, pela Comissão de Sindicância ou Inquérito Administrativo instituído pelo Conselho Municipal dos direitos da Criança e do Adolescente, que ela é inexistente, a candidatura poderá ser desconstituída. ${ }^{9}$

A idade mínima fixada em 21 anos tinha, até a revogação do Código Civil de 1916, uma função especial, pois com 21 anos atingia-se a maioridade civil. Assim, tal determinação tinha com objetivo não apenas garantir que os escolhidos tivessem capacidade plena, como uma pessoa emancipada, mas para garantir que efetivamente apenas pessoas com mais de 21 anos pudessem se candidatar.

É de se questionar, no entanto, se prevaleceria a idade de 21 anos se o ECA fosse revisado. Assim, Judá Jessé de Bragança Soares (apud CURY, 2006, p. 450) acredita que 0 inciso II do presente artigo exige a efetiva idade de 21 anos.

A lei também dispõe que o candidato deve residir no município, requisito relevante, uma vez que a função do conselheiro liga-se diretamente às características da cidade. Diante de seus conhecimentos sobre a sociedade, formação política, dificuldades econômicas, entre outras informações da localidade, o conselheiro terá ampliada sua capacidade de compreender os problemas apresentados e proceder diante deles.

${ }^{7}$ DIGIÁCOMO, Murillo José. Apenas o Conselho Tutelar não basta. Portal do Ministério Público do Estado do Paraná. Disponível em: ঝttp://www.mp.pr.gov.br/cpca/telas/ca_doutrina_cd_ct_9.html>. Acesso em: 15 mar. 2008.

${ }^{8}$ SIDOU, J. M. Othon. Dicionário Jurídico: Academia Brasileira de Letras Jurídicas. 9. ed. Rio de Janeiro. Forense Universitária, 2006. p. 433

${ }^{9}$ CUSTÓDIO, André Viana. A responsabilização do Conselheiro Tutelar. Boletim Jurídico, Uberaba, MG, v. 3, n. 203. Disponível em: «ttp://www.boletimjuridico.com.br/doutrina/texto.asp?id=1639>. Acesso em: 08 mar. 2008. 
Conveniente destacar que as funções de conselheiro acarretam responsabilidades para quem as exerce. Diante disso, a legislação federal deveria trazer previsões sobre o mau exercício, determinando punições, que nos casos mais graves geraria a perda do cargo. Assim, o CONANDA $^{10}$ expressa seu entendimento sobre a questão:

o Conselheiro Tutelar, a qualquer tempo, pode ter seu mandato suspenso ou cassado, no caso de comprovado descumprimento de suas atribuições, prática de atos considerados ilícitos, ou comprovada conduta incompatível com a confiança e outorga pela comunidade.

Para efeito de interpretação, o CONANDA considera como caso de cometimento de falta funcional grave, entre outras que possam ser aditadas pela municipalidade:

I- usar da função em benefício próprio;

II- romper sigilo em relação aos casos analisados pelo Conselho Tutelar que integre; III - manter conduta incompatível com o cargo que ocupa ou exceder-se no exercício da função de modo a exorbitar sua atribuição, abusando da autoridade que the foi conferida;

IV - recusar-se a prestar atendimento ou omitir-se a isso quanto ao exercício de suas atribuições quando em expediente de funcionamento do Consel ho Tutelar;

V - aplicar medida de proteção contrariando a decisão colegiada do Conselho Tutelar;

$\mathrm{VI}$ - deixar de comparecer no plantão e no horário estabelecido;

VII - exercer outra atividade, incompatível com o exercício do cargo, nos termos desta Lei.

VIII - receber, em razão do cargo, honorários, gratificações, custas, emolumentos, diligências. ${ }^{11}$

Assim, além dos requisitos trazidos pela lei, o conselheiro deve ser uma pessoa engajada e informada sobre sua função, o que não implica em formação acadêmica, mas sim na consciência da importância do trabalho dos conselheiros para a comunidade, de acordo com os princípios da proteção integral, proporcionalidade e igualdade.

A fim de que 0 atendimento seja efetivo, também se deve dar ênfase ao modo como ele é prestado, o local e se há necessidade de seus membros serem remunerados.

Art. 134. Lei municipal disporá sobre local, dia e horário de funcionamento do Conselho Tutelar, inclusive quanto a eventual remuneração de seus membros. Parágrafo único. Constará da lei orçamentária municipal previsão dos recursos necessários ao funcionamento do Conselho Tutelar.

${ }^{10}$ CONANDA - Conselho Nacional dos Direito da Criança e do Adolescente.

${ }^{11}$ CONANDA. Parâmetros de Funcionamento dos Conselhos Tutelares. Brasília: CONANDA, 2001. p. 15. 
A lei municipal deve estabelecer os horários de atendimento ao público. No caso de vários conselhos em um município, também deve estabelecer a divisão de competências, de acordo com limites territoriais.

Sobre a remuneração dos membros, vários doutrinadores acreditam que a remuneração deve se dar de acordo com a demanda apresentada. Algumas legislações municipais estabelecem remuneração apenas para um dos conselheiros, geralmente 0 "presidente". Deve-se atentar para a nomenclatura utilizada pelo legislador, constando na lei "seus membros", o que significa todos ou nenhum, ou seja, todo o órgão estará sujeito à escolha da legislação munícipe em remunerar ou não.

Digiácomo ${ }^{12}$ diz que na prática, o que ocorre é a desistência ou inoperância dos outros membros não-remunerados diante das dificuldades que o exercício da função apresenta. Assim, o órgão acaba por funcionar com apenas um membro efetivo, perdendo sua característica de colegiado. Além disso:

[E] se a Lei Federal ํ 8.069/90, em seu art.132 teve o cuidado de estabelecer que o Conselho Tutelar, cuja criação e manutenção é obrigatória em cada município, deve ser invariavelmente composto de 05 (cinco) membros, é deveras elementar que desejou o legislador que todos exercessem as mesmas funções, em absoluta igualdade de condições, pois quisesse ser flexível no número de componentes do órgão ou a eles conferir um tratamento diferenciado, o teria feito de maneira expressa, como aliás fez no que diz respeito à 'remuneração' dos conselheiros tutelares, que por força do disposto no art.134, caput do mesmo Diploma Legal, é apenas facultativa.

Além disso, Digiácomo ${ }^{13}$ acredita que por não haver nenhuma disposição acerca da possibilidade de diferentes classes de conselheiros, não há margem para sua criação em lei municipal. A função deve ser dotada de igualdade de direitos e deveres, sob pena de ferir 0 princípio constitucional da isonomia, presente no art. 5ํ, caput e I da Constituição Federal.

Deve-se considerar, além disso, que remunerar os membros do Conselho Tutelar tem, como principal função, servir para cobrir gastos advindos da execução de sua tarefa, a exemplo de deslocamento da residência para a sede do Conselho, e também para visitas (no caso de não haver transporte público específico para esse fim), alimentação, ou seja,

${ }^{12}$ DIGIÁCOMO, Murillo José. Algumas considerações sobre a Composição do Conselho Tutelar. Op. cit. ${ }^{13}$ Idem. 
[...] haverá Municípios onde se exigirá dos conselheiros tamanha dedicação que justificará uma remuneração razoável; em outros, bastará talvez um jeton para compensar eventuais perdas, e nos Municípios menores e mais pobres as funções poderão ser exercidas sem qualquer compensação financeira [... $]^{14}$

Os recursos necessários para o funcionamento do órgão devem constar no orçamento, abrangendo as despesas com o local de atendimento, transporte (se houver) e gastos com a efetiva utilização de possíveis instrumentos que a lei municipal disponibilizar, como computadores e eletrodomésticos. Do mesmo modo, deve constar a remuneração, se houver.

Todas as determinações que a lei faz em favor do cumprimento da função de conselheiro estão relacionadas à condição de serviço público relevante, conforme declara o seguinte artigo.

Art. 135. 0 exercício efetivo da função de conselheiro constituirá serviço público relevante, estabelecerá presunção de idoneidade moral e assegurará prisão especial, em caso de crime comum, até o julgamento definitivo.

Roberto João Elias (2004, p. 151) entende que por se tratar de serviço público relevante, há de se encontrar pessoas que exerçam a função com a finalidade única de servir a criança e 0 adolescente.

Desempenhar um serviço público relevante não transforma o conselheiro em servidor público, vez que o processo de seleção não o enquadra em estatutário nem celetista, a relação com o Estado não é permanente e não há dependência profissional ${ }^{15}$, não desfrutando de nenhuma das prerrogativas dos servidores, salvo se a lei municipal assim dispuser. Para fins de aposentadoria ou efeitos perante a previdência social, não há contagem de tempo de serviço, dependendo de disposição na legislação munícipe.

A prerrogativa de prisão especial no caso de crime comum pode representar um estímulo para o exercício do cargo (ELIAS, 2004, p. 151), ou uma honraria compensatória de contribuição (TAVARES, 2006, p. 141), não havendo opinião doutrinária consolidada a respeito.

\footnotetext{
14 MUNIR. Op. cit. página 452.

${ }^{15}$ BRANCO, Paulo José Azevedo. Natureza jurídica do conselheiro tutelar. Jus Navigandi, Teresina, v. 11, n. 1239, 22 nov. 2006. Disponível em: বhttp://jus2.uol.com.br/doutrina/texto.asp?id=9192>. Acesso em: 15 mar. 2008.
} 
Analisadas as prerrogativas, será feita uma análise sobre as atribuições do Conselho Tutelar, conforme determina o art. 136. Devido ao grande número de incisos desse artigo, os comentários serão tecidos separadamente.

Art. 136. São atribuições do Conselho Tutelar:

I - atender as crianças e adolescentes nas hipóteses previstas nos arts. 98 e 105, aplicando as medidas previstas no art. 101, I a VII;

Este inciso estabelece que o Conselho Tutelar deve agir quando algum direito reconhecido pelo Estatuto for ameaçado ou violado por ação ou omissão do Estado, da sociedade, dos pais ou responsável ou até mesmo de sua própria conduta, ou quando da prática de ato infracional. Assim, as medidas aplicáveis para cada uma dessas ocorrências estão previstas no art. 101, nos incisos I a VII, que tem como principal fundamento 0 auxílio para desenvolvimento de atividades positivas no desenvolvimento das crianças e adolescentes, como freqüentar a escola.

II - atender e aconselhar os pais ou responsável, aplicando as medidas previstas no art. 129, I a VII;

Os conselheiros também devem estar preparados para prestar atendimentos aos pais, e se necessário, aplicar as medidas previstas no art. 129, incisos I a VII, que têm como principais fins aconselhar, orientar ou até mesmo tratar, como é o caso da inclusão em programa de tratamento de alcoólatras e toxicômanos.

III - promover a execução de suas decisões, podendo para tanto:

a) requisitar serviços públicos nas áreas de saúde, educação, serviço social, previdência, trabalho e segurança;

b) representar junto à autoridade judiciária nos casos de descumprimento injustificado de suas deliberações.

O objetivo deste inciso é garantir a execução e cumprimento das medidas impostas pelo órgão. Entretanto, cidadãos e conselheiros estarão sujeitos à disponibilidade de serviços públicos, que quando não acessíveis, serão requisitados. Se o descumprimento for injustificado, o conselho deve comunicar o Juiz da Infância e Juventude, a fim de acarretar punição aos desobedientes (ELIAS, 2004, p. 154). 
IV - encaminhar ao Ministério Público notícia de fato que constitua infração administrativa ou penal contra os direitos da criança ou adolescente;

A obrigatoriedade de comunicar notícia de fato que constitua infração administrativa ou penal contra os direitos infanto-juvenis deve ser cumprida sob pena de responsabilidade do próprio Conselho, também em acordo com o previsto no art. 236 do Estatuto (ELIAS, 2004, p. 154).

Art. 236. Impedir ou embaraçar a ação de autoridade judiciária, membro do Conselho Tutelar ou representante do Ministério Público no exercício de função prevista nesta Lei:

Pena - detenção de seis meses a dois anos.

V - encaminhar à autoridade judiciária os casos de sua competência;

o Conselho também é obrigado a encaminhar, nos casos em que não for competente para agir, as crianças e adolescentes ao judiciário.

VI - providenciar a medida estabelecida pela autoridade judiciária, dentre as previstas no art. 101, de I a VI, para o adolescente autor de ato infracional;

Diante do estabelecimento de medida pela autoridade judiciária prevista no art. 101, I a VI, nos casos de adolescente infrator, o Conselho deve providenciar o seu cumprimento.

\section{VII - expedir notificações;}

Esta previsão deixa em aberto a função para a qual se destina. Notificar é dar conhecimento, comunicar, noticiar, comunicar solenemente, de acordo com as formalidades da $\mid \mathrm{lei}^{16}$, definição que ainda não possibilita compreender o objetivo real do inciso. Assim, esclarece Roberto João Elias (2004, p. 154):

[...] deve não ser só com relação aos pais e responsáveis, para que apresentem seus filhos ou tutelados, para serem ouvidos, mas também, em certos casos, às entidades que atendem menores, na co brança de alguma providência com respeito a menores, por força de medidas que foram aplicadas. Percebe-se, claramente que

${ }^{16}$ MELHORAM ENTOS. Minidicionário da Língua Portuguesa. 8. ed. São Paulo. Companhia Melhoramentos, 1994. Página 722. 
o legislador quis dar ao Conselho forças para que realmente possa atuar em prol da criança e do adolescente.

VIII - requisitar certidões de nascimento e de óbito de criança ou adolescente quando necessário;

Os conselheiros também terão a possibilidade de requisitar, gratuitamente, certidões de nascimento e de óbito, diante da necessidade ou a pedido dos pais ou responsável.

IX - assessorar o Poder Executivo local na elaboração da proposta orçamentária para planos e programas de atendimento dos direitos da criança e do adolescente;

0 intuito aqui é dar aplicabilidade ao previsto no art. 134, parágrafo único, que determina que quando da previsão orçamentária para os recursos destinados ao Conselho, os conselheiros deverão auxiliar na elaboração da proposta orçamentária.

$X$ - representar, em nome da pessoa e da família, contra a violação dos direitos previstos no art. 220, § 3o, inciso II, da Constituição Federal;

0 presente inciso dá instrumentalidade ao órgão para atuar na defesa dos direitos dos menores de idade, da família, a partir do determinado pelo art. 220, § 3ํ, II, CF, diante de programas de rádio ou televisão que contrariem o art. 221, CF, que determina que se deva dar preferência para finalidades educativas, culturais e artísticas. É curioso, então, proteger-se do não cumprimento de uma preferência, que não é uma determinação.

XI - representar ao M inistério Público, para efeito das ações de perda ou suspensão do pátrio poder.

Diante do entendimento do Conselho de afastar o poder familiar, seja permanentemente ou temporariamente, fica obrigado a representar ao Ministério Público, que deverá analisar as características do caso concreto para verificar se a perda ou suspensão do poder familiar ${ }^{17}$ se faz efetivamente necessária.

${ }^{17}$ O Código Civil de 2002 estabeleceu igualdade de condições à mulher em relação ao homem no que diz respeito à família e aos filhos, de modo que é mais adequada a nomenclatura poder familiar, que se refere ao núcleo familiar, de modo a superar a expressão pátrio poder, que se direcionava apenas ao pai. 
Para o cumprimento de suas atribuições, os conselheiros deverão tomar decisões, que diante de sua relevância, estão previstas no próximo artigo.

Art. 137. As decisões do Conselho Tutelar somente poderão ser revistas pela autoridade judiciária a pedido de quem tenha legítimo interesse.

Esse artigo em nada prejudica o que foi previsto pelo art. 131, que determina que 0 Conselho Tutelar é um órgão autônomo. Assim, diante do interesse de uma pessoa envolvida com decisões tomadas pelo conselho, existe a possibilidade de rever e analisar o que ficou determinado através da autoridade judiciária competente. Para tal, devem ser considerados interessados nas decisões tomadas pelo órgão o próprio menor, os pais ou responsável e o Ministério Público. É de se analisar se as pessoas que forem diretamente afetadas por esta decisão, a exemplo de diretores de escolas quando da obrigatoriedade de matrícula, entre outros responsáveis por órgãos públicos que requisitados para prestar atendimento (art. 136, III, a), também podem ser consideradas interessadas.

Segundo Roberto João Elias (2004, p. 155),

[...] o preceito constitucional do art. 5, XXXV,a lei não excluirá da apreciação do Poder Judiciário lesão ou ameaça a direito", é natural que as decisões do Conselho Tutelar possam ser revistas. Isso não representa de forma alguma, que o órgão é débil e não tem qualquer autonomia. Representa, isto sim, respeito a preceito universal, no sentido de que todas as questões podem e devem ser levadas ao Poder, que pode dirimi-las imparcialmente.

O estudo das funções do Conselho Tutelar deve estar ligado diretamente às suas competências, consolidando quais os serviços que devem ser prestado por cada unidade colegiada, conforme dispõe o próximo artigo.

Art. 138. Aplica-se ao Conselho Tutelar a regra de competência constante do art. 147.

Será competente para prestar atendimento o Conselho Tutelar segundo da localidade do domicílio dos pais ou responsável. Na ausência destes, considera-se o lugar onde se encontre a criança ou adolescente. Na ocorrência de ato infracional, a competência é do Conselho Tutelar do local onde ocorreu a ação ou omissão. "Há de se observar que, no tocante às medidas sócio-educativas aplicáveis a adolescentes, a competência é exclusiva da autoridade judiciária." (ELIAS, 2004, p. 157). 
Assim, encerra-se a análise sobre as atribuições do Conselho Tutelar, de modo que resta agora realizar uma análise acerca do modo como é realizada a escolha dos conselheiros, conforme traz 0 artigo seguinte.

Art. 139. 0 processo para a escolha dos membros do Conselho Tutelar será estabelecido em lei municipal e realizado sob a responsabilidade do Conselho M unicipal dos Direitos da Criança e do Adolescente, e a fiscalização do Ministério Público.

Como já dito anteriormente, quando da publicação original do ECA, o processo seletivo para os conselheiros era por meio de eleição, que também deveria ser estabelecido por Lei Municipal, e realizado sob a presidência de um Juiz eleitoral.

Pouco demorou para tornar perceptível a inconstitucionalidade de referido dispositivo, uma vez que a legislação sobre o processo eleitoral é privativa da União (art. 22, inciso I e art. 121 da Constituição Federal), sem possibilidade de delegação aos Municípios [...]. (MILANO FILHO; MILANO, 2004, arts. 139 a 140)

As semelhanças que o processo anterior e 0 atual mantém são a obrigatoriedade de fiscalização do Ministério Público e o estabelecimento em lei municipal de como deve se dar o processo. Assim, a responsabilidade passou das mãos do Juiz eleitoral para o Conselho Municipal dos Direitos da Criança e do Adolescente, que obviamente não irá presidir o processo de escolha, mas organizá-lo, no sentido de promovê-lo.

Diante da violação da legislação munícipe, caberá ao representante do Ministério Público mover perante o Juizado da Infância e Juventude competente as ações judiciais que se fizerem necessárias (TAVARES, 2006, 146).

É de se atentar para o fato de que, diferente de uma escolha de candidatos políticos, o sufrágio universal não será necessário. "A escolha pode ser indireta, desde que realmente representativa da comunidade local." (CURY, 2006, p. 464).

Assim, cabe a observação sobre o processo de escolha:

0 ideal, a nosso ver, é que as instituições públicas ou privadas que atuem há mais de um ano na proteção aos direitos das crianças e dos adolescentes (orfanatos, creches, escolas, centros de defesa) exercitem um papel semelhante ao dos partidos políticos, só elas indicando os candidatos para registro, em número estabelecido na lei municipal, quer seja direto, quer indireto, o processo de escolha. (CURY, 2006, p. 464). 
A legislação munícipe deve ter como principal objetivo garantir que o princípio da proteção integral seja respeitado, a partir da escolha de candidatos realmente dispostos a exercer a função de cuidar e assegurar que crianças e adolescentes tenham seus direitos intactos e cumpram com seus deveres.

Nos casos de impedimento, o ideal seria que eles fossem analisados anteriormente à escolha dos candidatos, de modo a sanar qualquer dúvida acerca de como proceder diante da escolha de um candidato impedido. Assim, procede-se agora com o estudo dos impedimentos.

Art. 140. São impedidos de servir no mesmo Conselho marido e mulher, ascendentes e descendentes, sogro e genro ou nora, irmãos, cunhados, durante 0 cunhadio, tio e sobrinho, padrasto ou madrasta e enteado.

Parágrafo único. Estende-se o impedimento do conselheiro, na forma deste artigo, em relação à autoridade judiciária e ao representante do Ministério Público com atuação na Justiça da Infância e da Juventude, em exercício na comarca, foro regional ou distrital.

Os impedimentos são claros ao determinar quais as pessoas que serão impedidas de servir no mesmo Conselho. José de Farias Tavares levanta o seguinte questionamento:

[...] se todas as pessoas são livres para apresentarem suas candidaturas, pois a lei não fixa tais impedimentos quanto à postulação (art. 133), como poderão ser, quaisquer delas, preteridas de exercer o mandato após serem eleitas?" (TAVARES, 2006, p. 147)

Interessante observar que, diante de um único Conselho no município, deve a lei municipal dispor que os casos de impedimentos sejam respeitados quando da candidatura. Entretanto, no caso de existirem vários Conselhos, existe a possibilidade de as pessoas impedidas de servirem juntas, exerçam a função em Conselhos diversos.

Judá Jessé de Bragança Soares (apud CURY, 2006, p. 468) dá sua interpretação sobre os impedimentos:

Os casos de impedimentos são taxativos, ou seja, não cabe interpretação extensiva. É princípio de Hermenêutica que as normas restritivas de direitos se interpretam restritivamente. Portanto, não são impedidos de servir no mesmo conselho, concubina e concubinário. 
Entretanto, é relevante destacar que na sociedade atual, o matrimônio de fato pode ser reconhecido como de direito, conforme dispõe o Código Civil:

Art. 1.723. É reconhecida como entidade familiar a união estável entre o homem e a mulher, configurada na convivência pública, contínua e duradoura e estabelecida com o objetivo de constituição de família.

Assim, diante desse artigo, os conviventes, que são reconhecidos como se casados fossem, devem ser tratados igualmente àqueles que são casados de direito, sendo, portanto, impedidos de servir num mesmo Conselho.

\section{Conclusão}

É perceptível que a Lei no 8.069/1990 é deveras evoluída para a sociedade de sua criação e também da sociedade de hoje. 0 que ocorre é o inverso do que deveria acontecer: a lei está sendo adaptada à realidade, quando, por sua característica de norma programática, a realidade deveria se transformar a partir da aplicação legal.

Em específico sobre o Conselho Tutelar, constatou-se diante dos estudos que este órgão enfrenta problemas orçamentários, muitas vezes não conta com sede própria e é duramente criticado. Mas é importante reconhecer que o trabalho com seriedade traz resultados muito positivos na proteção dos direitos da criança e do adolescente.

Também foi perceptível o desconhecimento por parte da comunidade, e até mesmo das pessoas que trabalham na área, das funções do Conselho Tutelar. Em relação à comunidade, em contato com conselheiros, foi dada a informação de que muitas pessoas procuram o órgão colegiado com o intuito de adotar uma criança, entre outros pedidos que não são de sua alçada.

Em relação aos profissionais, o apontamento surgiu a partir dos resultados do Projeto de Extensão "ECA na Docência do Ensino Fundamental e Médio"18. 0 projeto trabalhou com 11 questões relacionadas ao estatuto, com o intuito de levar maiores esclarecimentos para os professores, e também como ferramenta de adequação do trabalho à realidade de cada escola. Uma das questões se referia às funções do Conselho Tutelar, do

\footnotetext{
${ }^{18}$ Sob coordenação da Profa. Vilma A. do Amaral, Departamento de Direito Público da Universidade Estadual de Londrina, PROEX, 2006/2008.
} 
Ministério Público e do Judiciário, em que apenas 11\% dos 266 professores entrevistados relacionaram pelo menos uma função correta a cada um destes órgãos.

Assim, é de suma importância que o Conselho Tutelar seja desmistificado, desde suas normas de constituição e suas funções até seus impedimentos, pois o colegiado, como ente incumbido pela sociedade de tutelar pelos direitos das crianças e dos adolescentes, atua também de modo a transformar a sociedade, não apenas no aspecto da proteção, mas também no sentido de contribuir para a formação de pessoas preparadas para exercer a sua cidadania.

\section{Referências}

BRANCO, Paulo José Azevedo. Natureza jurídica do conselheiro tutelar. Jus Navigandi, Teresina, v. 11, n. 1239, 22 nov. 2006. Disponível em: বhttp://jus2.uol.com.br/doutrina/texto. asp?id=9192>. Acesso em: 15 mar. 2008.

BRASIL. Lei no. 8.069 de 13 de julho de 1990. Dispõe sobre o Estatuto da Criança e do Adolescente e dá outras providências. Disponível em:

বhttp://www.planalto.gov.br/ccivil_03/Leis/L8069.htm>. Acesso em: 10 mar. 2008.

BRASIL. Lei no. 8.242, de 12 de outubro de 1991. Cria o Conselho Nacional dos Direitos da Criança e do Adolescente \{Conanda\}e dá outras providências. Disponível em:

বhttp://www81.dataprev.gov.br/sislex/ paginas/42/1991/8242.htm>. Acesso em: 11 maio 2008.

CURY, M unir. Estatuto da Criança e do Adolescente Comentado: comentários jurídicos e sociais. 8. ed. São Paulo: Ed M alheiros, 2006.

CUSTÓDIO, André Viana. A responsabilização do Conselheiro Tutelar. Boletim Jurídico, Uberaba/MG, v. 3, n. 203. Disponível em:

বhttp://www.boletimjuridico.com.br/doutrina/texto.asp?id=1639>. Acesso em: $08 \mathrm{mar}$. 2008.

DA SILVA, José Afonso. Curso de Direito Constitucional Positivo. 27. ed. São Paulo: M alheiros Editores, 2006.

DIGIÁCOM O, Murillo José. Algumas considerações sobre a Composição do Conselho Tutelar. Portal do M inistério Público do Estado do Paraná. Disponível em: বtttp://www.mp.pr.gov.br/cpca/telas/ca_doutrina_cd_ct_13.html>. Acesso em: 15 mar. 2008. 
DIGIÁCOM O, Murillo José. Apenas o Conselho Tutelar não basta. Portal do M inistério Público do Estado do Paraná. Disponível em:

বhttp://www.mp.pr.gov.br/cpca/telas/ca_doutrina_cd_ct_9.html . Acesso em: 15 mar. 2008.

ELIAS, João Roberto. Comentários ao Estatuto da Criança e do Adolescente. 2. ed. São Paulo: Ed. Saraiva, 2004.

M ELHORAM ENTOS. Minidicionário da Língua Portuguesa. 8. ed. São Paulo: Companhia M elhoramentos, 1994.

M ILANO Filho, Nazir David e MILANO, Rodolfo César. Estatuto da Criança e do Adolescente: comentado e interpretado de acordo com o novo Código Civil. 2. ed. São Paulo: Liv. e Ed. Universitária de Direito, 2004.

M ORAES, Alexandre de. Direito Constitucional. 11. ed. São Paulo: Atlas, 2002.

PORTAL do Conselho Tutelar. Disponível em: $\varangle$ www. portaldoconselhotutelar.com.br>. Acesso em: 13 mar. 2008.

PORTAL do M inistério Público do Estado do Paraná. Disponível em: বhttp://www.mp.pr.gov.br>. Acesso em: 15 mar. 2008.

PORTAL do M inistério Público do Estado do Rio Grande do Sul. Disponível em: বhttp://www.mp.rs.gov.br>. Acesso em: 11 maio 2008.

SIDOU, J. M. Othon. Dicionário Jurídico: Academia Brasileira de Letras Jurídicas. 9. ed. Rio de Janeiro: Forense Universitária, 2006.

TAVARES, José de Farias. Comentários ao Estatuto da Criança e do Adolescente. 6. ed. Rio de Janeiro: Ed. Forense, 2006. 